\title{
Determination of Tritium Concentration in Heavy Water
}

\author{
Reza Pourimani*, Mehrdad Aghamohammadi \\ Department of Physics, Faculty of Science, Arak University, Arak, Iran \\ Email: ${ }^{*}$-pourimani@araku.ac.ir
}

Received 25 May 2014; revised 28 June 2014; accepted 8 July 2014

Copyright (C) 2014 by authors and Scientific Research Publishing Inc.

This work is licensed under the Creative Commons Attribution International License (CC BY). http://creativecommons.org/licenses/by/4.0/

c) (i) Open Access

\section{Abstract}

In this work, tritium concentration was determined in different $\mathrm{D}_{2} \mathrm{O}$ enrichment in heavy water samples. Samples were prepared from Arak Heavy Water Production Plant. Tritium concentration was determined utilizing liquid scintillation detector (LSC) system based on $\beta$-decay of tritium isotope. In this work instead of simple distillation, the azeotropic distillation method was used. Absorbed spectra and fluorescence spectra were registered by Shimadz spectrometer UV-2100 model and fluorescence spectrometer LS50B model respectively. Tritium concentration was obtained from $1.75 \pm 0.80$ up $6.16 \pm 1.01 \mathrm{~Bq} / \mathrm{L}$ for $0.35 \%$ to $77.50 \%$ enrichment of $D_{2} 0$ concentration in heavy water samples. Coefficient correlation between tritium concentration and $D_{2} 0$ concentration in heavy water $R^{2}=0.853$ was derived. For $99.8 \%$ enriched $D_{2} O$ in heavy water, deviation was observed from direct line that caused decreasing of $R^{2}$.

\section{Keywords}

Tritium, Liquid Scintillation Detector, Heavy Water, Correlation Coefficient, Azeotropic Distillation

\section{Introduction}

Tritium is a radioactive isotope having a half-life of 12.32 years; its concentration in natural water is about $10^{-18}$ atom of one atom of natural hydrogen. Tritium was discovered in 1934 by the physicists Ernest Rutherford, M. L. Oliphant, and Paul Harteck, who bombarded deuterium with high-energy deuterons according to the reaction $D(d, p) T$. Willard Frank Libby and Aristid V. Grosse showed that tritium is present in natural water, probably produced by the action of cosmic rays on atmospheric nitrogen [1]. Also tritium is produced most effectively by the nuclear reaction ${ }^{6} \mathrm{Li}(n, \alpha) T$ in nuclear-fission reactors. Although tritium reacts with other substances like ordinary hydrogen. The large difference in their masses sometimes causes marked differences in chemical prop-

"Corresponding author.

How to cite this paper: Pourimani, R. and Aghamohammadi, M. (2014) Determination of Tritium Concentration in Heavy Water. World Journal of Nuclear Science and Technology, 4, 170-176. http://dx.doi.org/10.4236/wjnst.2014.43022 
erties of the compounds. Thus, tritium is less commonly used than deuterium as an isotopic tracer for chemical reactions. The deuterium and tritium mixture can be heated to a temperature and pressure such that thermonuclear fusion occurs. Tritium is essential to the construction of boosted-fission nuclear weapons [2] [3]. A boosted weapon contains a mixture of deuterium and tritium, the gases being heated and compressed by the detonation of a plutonium or uranium device. The tritium beta decay to ${ }^{3} \mathrm{He}$ can be easily detected or can cause some other compound to fluorescence. Tritium is therefore used as a radioactive tracer element in biological research in the form of tritiated water (HTO or $\mathrm{T}_{2} \mathrm{O}$ ). It also is produced as a by-product of the operation of a heavy water reactor when neutrons are captured by deuterons or ternary fission of ${ }^{235} U$ [3] [4]. Because it emits very low energy radiation and leaves the body relatively quickly, for a given amount of activity ingested, tritium is one of the least dangerous radionuclides [5]-[7]. Since tritium always is in the water, it goes directly into soft tissues and organs. The absorbed dose by these tissues is generally uniform and dependent on the kind of tissues [5]-[7]. Concentration of tritium is sometimes reported in a "Tritium Unit" as TU, which is 1 tritium per $10^{18}$ hydrogen atoms, or 7.17 disintegrations per minute per $\mathrm{kg}$ of water or $0.118 \mathrm{~Bq} / \mathrm{L}$. Therefore, it is important to know that the tritium activity in drinking water should not be allowed more than $100 \mathrm{~Bq} / \mathrm{L}$ [4]. Tritium $\beta$-decay produce ${ }^{3} \mathrm{He}$ has high capture cross section for thermal neutrons as 5500 barn. For this reason determination of tritium concentration is very important in heavy water reactors and heavy water production plants that in these reactors heavy water is used as coolant and neutrons moderator. During heavy water production and heavy water reactor exploitation tritium concentration increases that is a poison material. The quantity of tritium released to the air and to water depends on the type of reactor. In pressurized water reactors (PWRs) most of the tritium that is released to the environment is produced by the interaction of neutrons with boron and lithium. The boron is added to the primary cooling water to control the rate of the nuclear fission in the fuel and the lithium is added for controlling corrosion. This is not an issue for boiling water reactors (BWRs), because any boron or lithium is not added to the primary water [5].

Tritium also is produced, in greater quantities, in the fuel rods of both PWRs and BWRs from ternary fission. The PWRs cooling water is constantly taken out for chemical treatment, volume control, and reduction of the radioactivity. Then most of it is sent back into the reactor vessel. Some of the fission products that leak into the primary water of the reactor are removed by passing the water through ion exchange resins. However, this process does not affect triturated water being chemically identical to water [6]-[9]. The part of the cooling water which is not returned to the reactor vessel is put in holding tanks. It is periodically released to the environment after further treatment and dilution to bring the tritium concentration to a level deemed safe by the nuclear industry according to NRC regularity. As radioactive water, tritium can cross the placenta, posing some risk of birth defects and early pregnancy failures. Ingestion of triturated water also increases cancer risk [10] [11].

\section{Materials and Methods}

Seven samples of heavy water with different of $\mathrm{D}_{2} \mathrm{O}$ concentration in $\mathrm{H}_{2} \mathrm{O}: 0.35 \%, 13.5 \%, 35.20 \%, 56.16 \%$, $58.20 \%, 77.50 \%$ and $99.80 \%$ were prepared from Arak Heavy Water Plant. Samples prepared in laboratory with special conditions. Heavy water mixed with demineralizied light water and for controlling process, heavy water concentration determined using infra-red methods. $250 \mathrm{ml}$ of each sample was filtered by Whatman paper. In order to eliminate metal and radionuclides interferences and to prevent exit of $\mathrm{H}_{2}$ gas from samples, $0.5 \mathrm{~g}$ sodium hydroxide $(\mathrm{NaOH})$ was added to $100 \mathrm{ml}$ aliquot of the filtered samples. In addition, $0.1 \mathrm{~g}$ potassium permanganate $\left(\mathrm{KMnO}_{4}\right)$ was added for oxidizing trace organics in sample aliquots to eliminate quenching interferences. After mixing thoroughly, $10 \mathrm{ml}$ cyclohexane solvent was added to create azeotrope in water sample. Then it was distillated at $75^{\circ} \mathrm{C}$. Distillation apparatus has been shown in Figure 1. The distillated water sample transferred to azeotrope vessel. $10 \mathrm{ml}$ of bottom layer (aqueous phase) was collected and cooled at room temperature. An aliquot of $10 \mathrm{ml}$ was transferred to a clean scintillation counting vial. Add 10-ml of Ultima Gold's scintillation cocktail. Vial shacked well for 15 minutes. To maximize efficiency of radio luminescence from $\beta$ decay source, samples have been hold at $4^{\circ} \mathrm{C}$ for one hour. The same procedure was done for blank and standard sample. The blank sample with very low tritium content was prepared from the most deep well water sources. A Perkin Elmer luminescence spectrophotometer Model LS50B was used for fluorescence spectrum measurements and a Shimadzu absorbance double beam photo spectrometer Model UV-2100 was used for absorbance spectrum measurements to approve complete removing organic and inorganic impurity which make luminescence quenching in samples The finally counting registered by two LSC detector Malisa Star Counter Measurement 


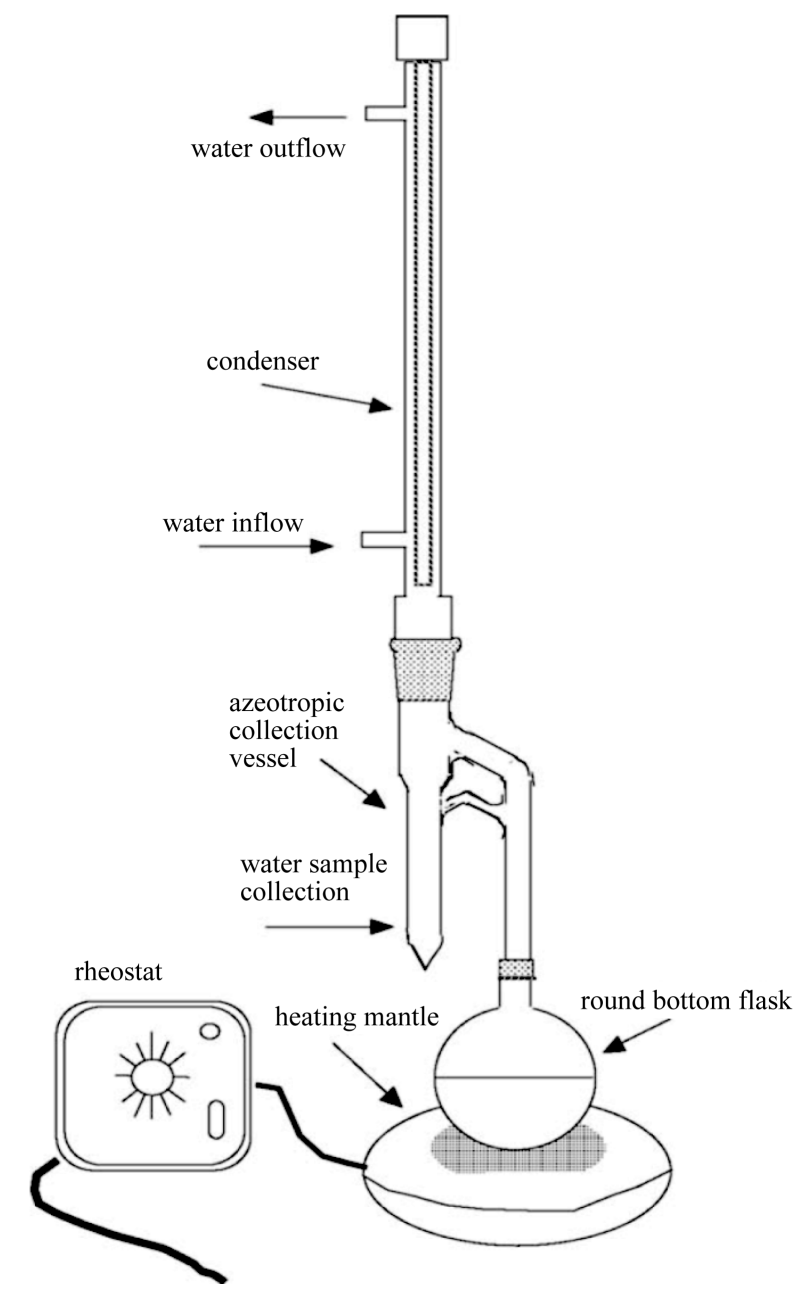

Figure 1. Scheme of distillation apparatus schematic.

model ST003-2 have taken in shielding of $\mathrm{Pb}$ in coincidence system.

All chemical materials and reagents used in this study were of analytical-reagent grade. Deionized water was used to prepare all the solutions. The laboratory glassware was washed with deionized water. All chemical materials such as potassium permanganate, sodium hydroxide, acetone, methanol, cyclohexane and sulfuric acid were prepared from Merck's Company. The Ultima Gold cocktail brand (based on ethoxylated-alkylphenol, naphthalene solvent, which very low vapor pressure and high flash point) was prepared from Perkin Elmer's Company. For confide to disappear organic and inorganic impurity in samples that cause to quenching, all heavy water samples were distillated and collected in azeotrope vessel, registered absorbed spectrum in wavelengths range from 190 to $1100 \mathrm{~nm}$ by UV-2100 Shimadzu

\section{Analytical and Numerical Calculations}

Tritium activity of samples, $A C$, for each aliquot can be obtained from formula (1) [12] [13]:

$$
A C=\frac{R_{a}-R_{b}}{\epsilon \times F \times V \times \mathrm{e}^{-\lambda t}}
$$

where: $R_{a}, R_{b}, \epsilon, F, V, \lambda$ and $t$ are sample aliquot gross count rate $\left(\mathrm{s}^{-1}\right)$, background aliquot count rate $\left(\mathrm{s}^{-1}\right)$, detection efficiency, recovery factor, volume of the sample aliquot (ml), decay constant of tritium (day ${ }^{-1}$ ), elapsed time between sampling and counting in days respectively.

The result of the measurement has an uncertainty due to counting statistics (counting uncertainty). The com- 
ponent of the combined standard uncertainty of the tritium concentration measurement in the sample due to counting statistics, $u_{c C}(A C)$, is given by Equation (2):

$$
u_{c C}(A C)=\frac{\sqrt{\frac{R_{a}}{t_{a}}+\frac{R_{b}}{t_{b}}}}{\epsilon \times F \times V \times \mathrm{e}^{-\lambda t}}
$$

where $t_{b}$ is count time of the background sample in second. For calculation the parameters of formula as $\varepsilon$ and its uncertainty can be used the Equations (3) and (4).

$$
\begin{aligned}
& \epsilon=\frac{R_{D W T S}-R_{b}}{A_{D W T S}} \\
& u(\epsilon)=\sqrt{\frac{\frac{R_{D W T S}}{t_{D W T S}}+\frac{R_{b}}{t_{b}}}{A_{D W T S}^{2}}+\epsilon^{2}\left(\frac{u\left(A_{D W T S}\right)}{A_{D W T S}}\right)^{2}}
\end{aligned}
$$

where $\epsilon, A_{D W T S}, R_{b}, R_{D W T S}, u\left(A_{D W T S}\right), t_{D W T S}$ and $t_{b}$ are efficiency, activity of distilled water tritium standard $(\mathrm{Bq})$, background aliquot count rate $\left(\mathrm{s}^{-1}\right)$, standard uncertainty of the activity $A_{\mathrm{DWTS}}$ (Bq), count time for the distilled water tritium standard (seconds), count time for the background sample (s) respectively [12] [13].

Values of detection efficiency and uncertainty of detection efficiency are equal to 2.107 and 0.003 respectively [12]. Recovery correction factor, $F$ can be derived according to formula (5).

$$
F=\frac{R_{D W T S}-R_{b}}{\epsilon \times A_{R W T S}}
$$

where $A_{R W T S}$ is activity of undistilled raw water tritium standard (Bq) [14].

In this work recovery correction factor is obtained as 0.986 .

The minimum detectable activity (MDA) is usually used to discriminate a measurement from the background. MDA was evaluated using the relation (6) [15].

$$
\mathrm{MDA}=\frac{2.71+3.29 \sqrt{R_{b} \times t_{a} \times\left(1+\frac{t_{a}}{t_{b}}\right)}}{\epsilon \times t_{a} \times F \times V \times \mathrm{e}^{-\lambda t}}
$$

where $R_{b}, t_{a}$ and $t_{b}$ are background count rate $\left(\mathrm{s}^{-1}\right)$, counting time of sample (s), counting time of background (s) respectively.

\section{Figure of Merit}

Tritium beta particle is counted with a window setting, where the Figure Of Merit (FOM) is at maximum that indicates signaling to noise ratio according to relation (7).

$$
\mathrm{FOM}=\frac{\epsilon^{2}}{R_{b}}
$$

In this work FOM obtained equal to 3.29 seconds [13] [16] [17].

\section{Results and Discussion}

The result was recorded in absorbed spectrum of sample with heavy water concentration $99.80 \%$ in light water, indicate that absorbance is about zero, therefore cleanup is complete and there is not color quenching in prepared samples, see Figure 2.

Then fluorescence spectrum with excitation wavelength $250 \mathrm{~nm}$ was registered in wavelengths range from 400 to $800 \mathrm{~nm}$ by LS50B Perkin Elemer apparatus. Results of luminescence in sample of heavy water concentration $99.80 \%$ have been shown in Figure 3. Luminescence after distillation and cleanup is about zero, therefore is azeotrope method distillation without any interfering substance in analysis tritium. Result of activity and 
MDA calculation can be found in Table 1 and Table 2 respectively. Figure 4 shows a regression linear trend of tritium concentration in samples of heavy water enrichments. The data indicate that the tritium concentration in samples of heavy water, correlate with enrichment of $\mathrm{D}_{2} \mathrm{O}$ in light water.

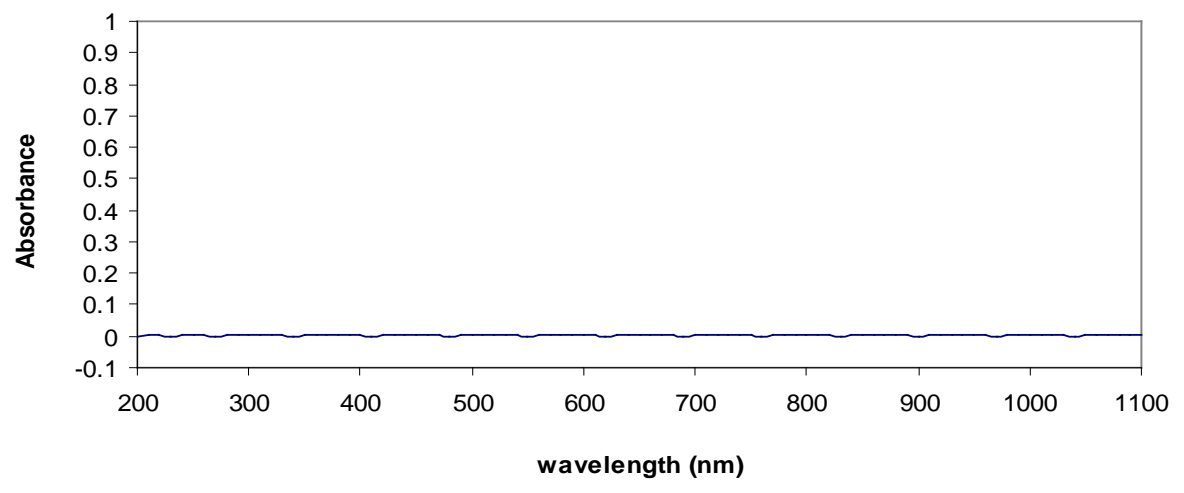

Figure 2. Absorbance spectrum of $99.8 \%$ heavy water enrichment sample.

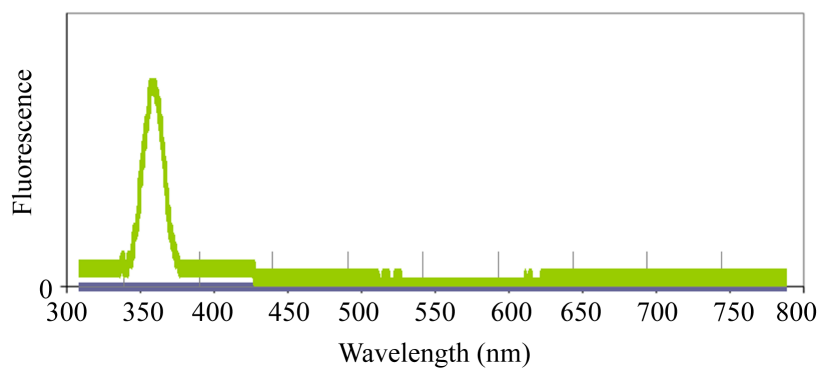

Figure 3. Fluorescence spectrum of $99.8 \%$ heavy water enrichment ample.

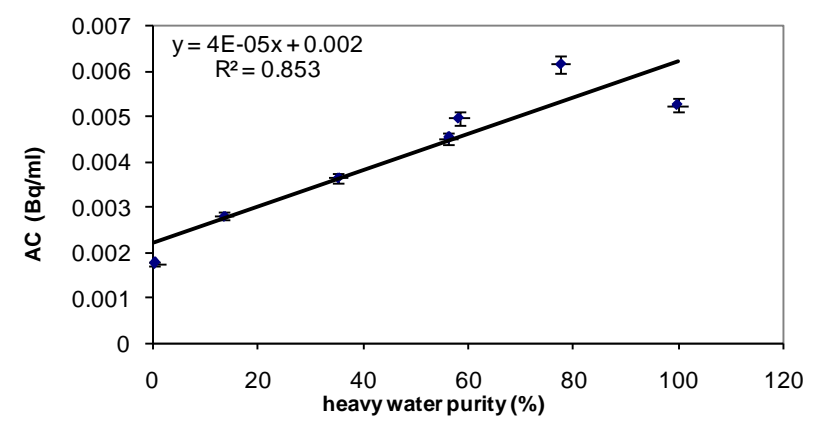

Figure 4. Plot of tritium concentration versus percentage of heavy water enrichment.

Table 1. Results of measurement of Tritium concentration in heavy water.

\begin{tabular}{|c|c|c|c|c|}
\hline Heavy water enrichment (\%) & $A C \quad \mathrm{~Bq} / \mathrm{L}$ & $u_{c C}(A C) B q / L$ & $T U$ & $u_{c C}(T U)$ \\
\hline Tritium standard water (DWS) & 1661.15 & 2.50 & 14077.55 & 21.18 \\
\hline 0.35 & 1.75 & 0.80 & 14.86 & 6.78 \\
\hline 13.50 & 2.80 & 0.90 & 23.81 & 7.63 \\
\hline 35.20 & 3.66 & 0.90 & 30.99 & 7.63 \\
\hline 56.16 & 4.52 & 0.90 & 38.32 & 7.63 \\
\hline 58.20 & 4.98 & 0.90 & 42.18 & 7.63 \\
\hline 77.50 & 6.16 & 1.00 & 52.18 & 8.47 \\
\hline 99.80 & 5.26 & 0.90 & 44.59 & 7.63 \\
\hline
\end{tabular}


Table 2. Calculated values of minimum detectable activity concentration.

\begin{tabular}{cc}
\hline Heavy water enrichment (\%) & MDA $\mathrm{Bq} / \mathrm{L}$ \\
\hline Tritium standard water (DWS) & 12.2 \\
0.35 & 1.4 \\
13.50 & 2.2 \\
35.20 & 2.9 \\
56.16 & 2.9 \\
58.20 & 2.9 \\
77.50 & 3.2 \\
99.80 & 2.9 \\
\hline
\end{tabular}

The tritium activity concentration in final production heavy water enriched in $99.8 \% \mathrm{D}_{2} \mathrm{O}$ of Heavy Water Plant in Arak city, Iran' production is $5.60 \pm 0.90 \mathrm{~Bq} / \mathrm{L}$ that is more than its natural value. Tritium value in natural water is about 3.5 TU, while in this production is about $47.5 \mathrm{TU}$. Since the maximum contaminant level for tritium in drinking water as given in the National Interim Primary Drinking Water Regulations (NIPDWR) is $20,000 \mathrm{pCi} / \mathrm{l}[15]$. $1 \mathrm{TU}$ is equal to $3.23 \mathrm{pCi} / \mathrm{l}$, therefore the tritium activity concentration measured in these samples is lower than National Interim Primary Drinking Water Regulations (NIPDWR). Hence, on the basis of nuclear regulatory commission (NRC) and NIPDWR values determined by European Union, the obtained results show no environmental and biological hazard. The heavy water reactors should be in attention primary tritium concentration and its variation along the reactor exploitation as poison.

\section{References}

[1] Lucas, L.L. and Unterweger, M.P. (2000) Comprehensive Review and Critical Evaluation of the Half-Life of Tritium. Journal of Research of the National Institute of Standards and Technology, 105, 541-549.

[2] Fireman, E.L., Defelice, J. and Tilles, D. (1961) Solar Flare Tritium in a Recovered Satellite. Physical Review, 123, 1935. http://dx.doi.org/10.1103/PhysRev.123.1935

[3] Nir, A., Kruger, S.T., Lingenfelter, R.E. and Flamm, E.J. (1966) Natural Tritium. Reviews of Geophysics, 4, 4-441.

[4] Thompson, R.C. and Ballou, J.E. (1954) Studies of Metabolic Turnover with Tritium as a Tracer: IV Metabolically Inert Liquid and Protein Fractions from the Rat. The Journal of Biological Chemistry, 208-228.

[5] Glasstone and Sesonske (1981) Nuclear Reactor Engineering. 3rd Edition, Van Nostrand Reinhold, New York, 9-119.

[6] National Council on Radiation Protection and Measurements (1979) Tritium in the Environment. Recommendations of NCRP, NCRP, Bethesda, Report No. 62.

[7] Dyadin, Yu.V., et al. (1979) Measurement of Tritium Concentration in Heavy-Water Reactor. Atomnaya E`nergiya, 47, 321-323.

[8] Radioactive Effluent and Environmental Reports. http://www.nrc.gov/reactors/operating/opsexperience/tritium/plant-info.html

[9] Harold, T., Peterson, B. and David, A. (1985) Tritium Production, Releases and Population Doses of Nuclear Power Reactors. Fusion Technology, 8, 2544-2550.

[10] NAS-NRC (2006) Health Risks from Exposure to Low Levels of Ionizing Radiation: BEIR VII-Phase2. National Research Council of the National Academies.

[11] Makhijani, A. (2008) The Use of Reference Man in Radiation Protection Standards and Guidance with Recommendations for Change.

[12] Annual Book of ASTM Standards (1978) Part 31, American Society for Testing and Materials. Philadelphia, Pennsylvania.

[13] (1976) EPA Drinking Water Regulations. Federal Register, Vol. 41, No. 133, Friday, July 9, Title 40, Part 141.

[14] Hilmen, E.-K. (2000) Separation of Azeotropic Mixtures: Tools for Analysis and Studies on Batch Distillation Operation. Norwegian University of Science and Technology, Trondheim.

[15] (1976) Standard Methods for the Examination of Water and Waste Water. 14th Edition, American Public Health Association, Washington. 
[16] Moghissi, A.A., Bretthauer, E.W. and Compton, E.H. (1973) Separation of Water from Biological and Environmental Samples for Tritium Analysis. Analytical Chemistry, 45, 1565-1566.

[17] Sodd, V.J. and Scholz, K.L. (1969) Analysis of Tritium in Water; A Collaborative Study. Journal of the Association of Official Analytical Chemists, 54, 1. 
Scientific Research Publishing (SCIRP) is one of the largest Open Access journal publishers. It is currently publishing more than 200 open access, online, peer-reviewed journals covering a wide range of academic disciplines. SCIRP serves the worldwide academic communities and contributes to the progress and application of science with its publication.

Other selected journals from SCIRP are listed as below. Submit your manuscript to us via either submit@scirp.org or Online Submission Portal.
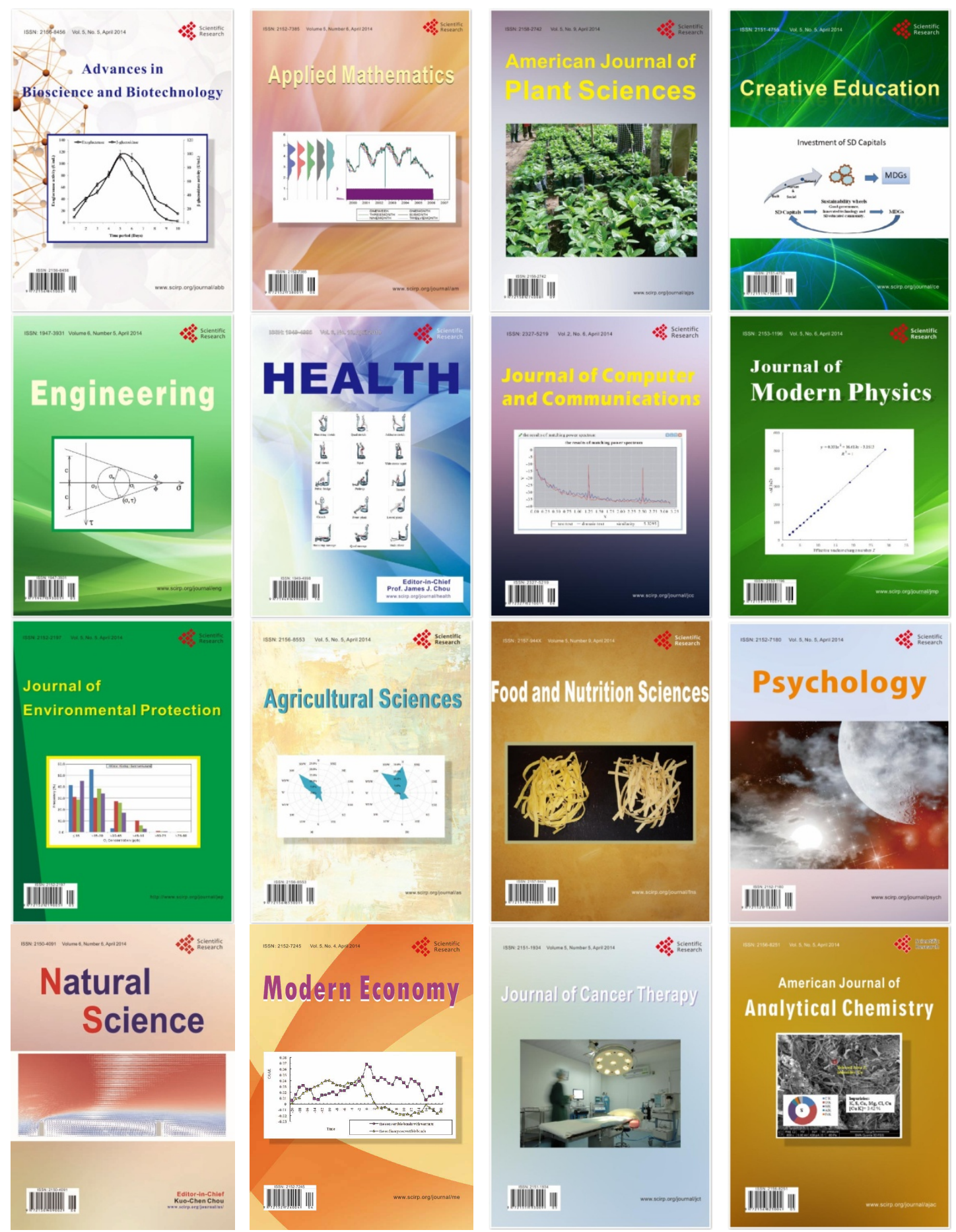